\title{
JOB SATISFACTION OF AGRICULTURE GRADUATES WORKING UNDER GOVERNMENT GRADUATE SCHEME
}

\author{
${ }^{1}$ Sandika AL and ${ }^{1}$ Kalansuriya NK ${ }^{*}$ \\ ${ }^{1}$ Department of Agricultural Economics and Extension, Faculty of Agriculture, University of Ruhuna, Sri \\ Lanka
}

Accepted: 06 February 2014

\begin{abstract}
This study attempted to investigate the job satisfaction of Agricultural Graduate (AG) employed under the Government Graduate Scheme using a structured pre-tested questionnaire. The aims of the study were to identify problems faced by the AG and to suggest appropriate measures to enhance their job satisfaction. Fifty AG were selected from provincial and inter-provincial government institutes to collect the primary data. Respondents were classified into three levels of job satisfaction such as satisfied, indifferent and dissatisfy. Majority of AG (68\%) were in the dissatisfaction level while $28 \%$ indicated indifferent level and only few (4\%) found to be satisfied in their assigned jobs.
\end{abstract}

\begin{abstract}
We used the Frederick Herzberg's Motivator and Hygiene factors to determine the job satisfaction of AG. A majority of AG fell into dissatisfaction level regarding Hygiene factors of Herzberg's Motivation theory such as salary $($ Mean $=-\mathbf{0 . 5 9}, \mathrm{SD}=1.1$ ), payment relate to education level $($ Mean $=-1.14, \mathrm{SD}=0.89)$, performance appraisal (Mean $=\mathbf{- 0 . 7 7}, \mathrm{SD}=\mathbf{0 . 9 7}$ ), availability of facilities / resources at work place $($ Mean $=0.14, \mathrm{SD}=\mathbf{0 . 9 4})$, recognition for creative works $($ Mean $=\mathbf{- 0 . 1 8}, \mathrm{SD}=1.01)$, scope to prove excellence in doing the job $($ Mean $=0.09, \mathrm{SD}=1.01)$, opportunities for higher education and trainings (Mean $=\mathbf{- 0 . 4 5}, \mathrm{SD}=1.06)$ and promotion opportunities (Mean $=$ $1.18, S D=1.14)$. Nevertheless, respondents were in the satisfaction level on motivators factors such as regards guidance given by superiors to improve job (Mean $=0.23, \mathrm{SD}=0.87$ ), with the flexibility that AGs have been given by their superior $($ Mean $=0.32, \mathrm{SD}=1.09)$, distance from office to house $($ Mean $=0.27, \mathrm{SD}=1.24)$, opportunities provided to utilize personal skill (Mean $=\mathbf{- 0 . 0 5}, \mathrm{SD}=\mathbf{1 . 0 5}$ ), recognition from superior officers for good work done (Mean $=0.09, \mathrm{SD}=1.02)$, mutual understanding with the co-workers (Mean $=1.05, \mathrm{SD}=0.65)$ and flexibility to engage with family responsibilities, children's education etc. $($ Mean $=0.27, S D=1.08$ ). Result of this study showed that salary and awareness about job description had showed positively significant relationship with job satisfaction while experience had showed negatively significant relationship with job satisfaction. Other personal and job related variables were not correlated with job satisfaction.
\end{abstract}

\section{INTRODUCTION}

In Sri Lanka, there are 15 state managed universities with an average annual output of about 20,000 graduates. Among these universities, 8 offer agriculture related degrees and nearly thousand agriculture graduates (AG) passing out annually with BSc degrees. The Sri Lankan society believes that that government should provide job opportunities for all graduates passing out from these higher Education Institutions (HEI). As a result of the political pressure, the government recruits graduates under different programs/schemes like Graduate Scheme (GS) that was introduced in 2012. A large number of graduates $(50,800)$ were absorbed to various government organizations under this GS program, (www.infolanka.com). This scheme also recruited a large number of *Corresponding author: nilantha.kls@gmail.com
AG to work in government organization responsible for agriculture and allied fields. Majority of AGs selected this scheme by resigning their jobs in private or non-governmental organizations. However, accepting new jobs under this scheme a majority of AG accuse that the job satisfaction is very low.

The word job satisfaction (JS) has become most vital phenomenon in the career management literature. The JS, a worker's sense of achievement and success, is generally perceived to be directly linked to productivity as well as to personal wellbeing. JS implies doing a job one enjoys, doing it well, and being suitably rewarded for one's efforts. It further implies enthusiasm and happiness with one's work. JS can be defined as "a collection of feelings that an individual holds towards his or her 

job" (Robins et al. 2005); an affective reaction to one's job (Cranny and Stone 1992); and an attitude towards one's job. In accordance with the career management literature, different reasons may lead to reduce JS and several of them consist of nonexistence of career plateau, lack of individual skills \& abilities, lack of intrinsic motivation, lack of extrinsic reward, stress, demographic variables, personal orientation factor and work environment perception. The employees with low level of JS often shows deteriorate in performance and productivity, low level of organizational commitment and loyalty (Alen et al. 1998). So, it creates a negative impact to organizations. Negative JS should not be considered as a problem of an organization alone. In general, an economy and society consist of so many socio and economic institutions. These institutions are inter-related in nature. Hence it should be understood that if the negative JS of an individual worker not only affects the institutions and organization of an economy as well.

Government of Sri Lanka expects rapid development of agriculture at grass root level through this program. The success of these efforts depends on interest of the farmers and grass root level government officers towards the program. If the above are not satisfied, government cannot expect a grass root level development leading to a breakdown of the program. Hence, the main objective of this study was, to investigate the JS of AG working under GS and to identify the problems face by them. In addition, the project expects to suggest appropriate measures to overcome the identified problems.

\section{METHODOLOGY}

In order to achieve objectives, both primary and secondary data were collected. Southern province of Sri Lanka was selected purposively as the study area since this province has immense potential to develop the agriculture sector. The randomly selected AG, who are working in the GS in province and inter-province government departments were selected to collect the primary data. List of AGs who are working in the province and inter-province government department was used as sample frame of this study. By considering the objectives of the study structured questionnaire was used to collect the primary data from the sample of 50. Herzberg's two factor theory proposed two dimensions to job satisfaction: motivation and hygiene. Hygiene issues, according to Herzberg, cannot motivate employees but can minimize dissatisfaction if management would handle employees properly. Motivators on the other hand, create satisfaction by fulfilling individuals' needs for meaning and personal growth. According to Newstrom and Davis (2004), JS is a set of favorable or unfavorable feelings and emotions with which employees view their work. At this background, it was operationalized as the degree to which a respondent is satisfied or not satisfied with different aspects of his job. This variable was quantified by using the scale developed by Manjula (2000). The scale consisted of 15 statements expressing different aspects of job satisfaction. The respondents were asked to mention the appropriate answers for each statement of the scale which had Likert-scale with five points from highly satisfied to highly dissatisfied with scores of $+2,+1,0,-1$ and -2 score, respectively. JS score of a respondent was obtained by summing up the scores obtained by him on all the statements. Further, respondents were classified into three categories such as satisfied, indifference and dissatisfied based on range.

Variables such as gender, age, education, previous work experience, training received, salary of previous job, reason to joint for GS, way of updating the knowledge, awareness of job profile, satisfaction about job profile, and duty list, problems identified and suggestions for overcome them are some of variables that asked to achieve objectives. Position name, satisfaction on duties, dedication on work, facilities provide were some factors measured with based on five- point Likert scale $(+2=$ 
strongly agree to $-2=$ strongly disagree). The collected data were analyzed by using frequency and percentage, factor, simple correlation, multiple regression analysis. The secondary data were gathered through reports, journals, newspapers, internet etc. The data were analyzed by using Pearson correlation.

\section{RESULTS AND DISCUSSION}

The survey revealed that the majority of respondents were in the dissatisfaction category while rests were in indifferent level. According to the aggregate score of the respondents, they have been classified into three different levels of JS such as satisfied, indifferent and dissatisfied. It was clear that the highest frequency $(68 \%)$ was recorded under dissatisfied level.

\section{Table 1: Job satisfaction of AGs}

\begin{tabular}{cll}
\hline Categories & Number & Percentage \\
Job satisfaction & & \\
Satisfied & 2 & 04 \\
Indifferent & 14 & 28 \\
Dissatisfied & 34 & 68 \\
\hline $\mathbf{N =} \mathbf{5 0}$ & &
\end{tabular}

It was indicated that more respondents were suffering from very low job satisfaction. Indifferent and satisfy levels have indicated as $28 \%$ and $4 \%$ respectively.

This result was contradictory with the result of the study conducted by Sandika and De Silve (2011) for the Agriculture Instructors (AIs). With regard to JS of the AIs, majority $(79 \%)$ of respondents were indifferent level. It means that majority was in neither satisfied nor dissatisfied levels. Further, 11 and 10 percent of respondents were in dissatisfied and satisfied level, respectively. Further result of this study was not alien with the results found by the Nagananda (2005) from his study conducted at India. He found 65.75 percent of Assistant Directors of Agriculture and 75.70 percent of Agriculture Officers perceived medium level of job satisfaction, while 16.7 percent of Assistant Directors of Agriculture and $5.00 \%$ of Agriculture Officers perceived high level of job satisfaction.

According to Herzberg, Frederick 1968 Motivator and Hygiene factors affect to JS of employees. This study attempted to analysis how those factors affect to JS of AG who are working under GS. Different dimensions were considered to investigate Motivator and $\mathrm{Hy}$ giene factors. The study revealed that $A G$ were dissatisfied with their job due to low salary $($ Mean $=-0.59, \mathrm{SD}=1.1$ ), insufficient payment relate to their education level (Mean $=-1.14, \mathrm{SD}=0.89)$, poor performance appraisal $($ Mean $=-0.77, \mathrm{SD}=0.97)$, inadequate facilities and resources at work place (Mean $=$ $0.14, \mathrm{SD}=0.94)$, lack of recognition for creative works $($ Mean $=-0.18, \mathrm{SD}=1.01)$, low scope to prove excellence in doing the job (Mean $=0.09, \mathrm{SD}=1.01$ ), low opportunities for higher education and trainings (Mean = $0.45, \mathrm{SD}=1.06$ ) and absence of promotion opportunities $($ Mean $=-1.18, \mathrm{SD}=1.14)$. According to Herzberg theory, above indicated factors belong to hygiene factors. When hygiene factors were absent it creates dissatisfaction.

Therefore, relevant authorities should pay attention to implement appropriate measures in order to increase the JS of the AGs. Nevertheless, respondents have satisfaction level on motivators factors regarding guidance given by superiors to improve job (Mean $=0.23, \mathrm{SD}$ $=0.87$ ), with the flexibility that AGs have been given by their superior (Mean $=0.32$, $\mathrm{SD}=1.09$ ), distance from office to house (Mean $=0.27, \mathrm{SD}=1.24)$, opportunities provided to utilize personal skill (Mean $=-0.05$, $\mathrm{SD}=1.05)$, recognition from superior officers for good work done $($ Mean $=0.09, \mathrm{SD}=1.02)$, mutual understanding with the co-workers (Mean $=1.05, \mathrm{SD}=0.65)$ and flexibility to engage with family responsibilities, children's education etc. $($ Mean $=0.27, \mathrm{SD}=1.08)$. 
From the sample $56 \%$ were male and rest $44 \%$ were female. When considering their age, mean value of the age of respondents were 36 (range 28 - 43 years). Further, majority of $(64 \%)$ were in $31-40$ years age category. Only 10 respondents $(20 \%)$ were in below to 30 years and $16 \%$ (08 respondents) were in more than 40 years. The AG had very poor $(88 \%)$ desire for postgraduate studies.

In case of job experience, total job experience was varied from 17 to one year with the 8 year mean job experience. About $40 \%$ and $36 \%$ respondents were in the category of 05 to 10 year and more than 10 year experience categories, respectively. It clearly shown that majority of agriculture graduate have done various jobs at private sector before joint to the government scheme. Further, 28 (57\%) of respondents have worked under private sector before joint to the scheme. On this background, it can be recognized that preference for the governments by the agricultural graduates. However, jobs implementing of job scheme may badly affects to the performance of the private sector. On the other hand, negative impression regarding Agricultural Graduate may develop in the private sector and they may hesitate to provide the job opportunities for the graduate in future due to this reason.

Salary of the previous job was also considered factor of this study. Salary of previous job was recorder as SLRs 40000.00 to SLRs 8 000.00 with the mean of SLRs 16334.00 . This result clearly illustrates that agricultural graduates have given up their previous job though they were paid relatively considerable amount salary. Therefore, reason for joining to scheme was studied. It was observed that finding a government job as reason for joining to scheme. It means that graduates consider job security first that the salary. This result however was not aligned with the Maslow's hierarchy need theory. It could be observed from Table 2 that majority of AG $(68 \%)$ had received at least one training in their entire working period.
Table 2: Personal characteristics of the respondents

\begin{tabular}{|c|c|c|}
\hline Variables \& Categories & $\begin{array}{l}\text { No.of } \\
\text { spondents }\end{array}$ & $\%$ \\
\hline \multicolumn{3}{|l|}{ Gender } \\
\hline Male & 28 & 56 \\
\hline Female & 22 & 44 \\
\hline \multicolumn{3}{|l|}{ 2. Age (Year) } \\
\hline Young $(<30)$ & 10 & 20 \\
\hline Middle (31-40) & 32 & 64 \\
\hline Old $(>41)$ & 08 & 16 \\
\hline \multicolumn{3}{|l|}{ 3. Education (Grade) } \\
\hline Degree & 44 & 88 \\
\hline Post Graduate & 06 & 12 \\
\hline \multicolumn{3}{|l|}{ 4. Job experience (Years) } \\
\hline Less than 05 & 12 & 24 \\
\hline $06-10$ & 20 & 40 \\
\hline Higher than 19 & 18 & 36 \\
\hline \multicolumn{3}{|c|}{ 4. Number of training received from previous job } \\
\hline No & 16 & 32 \\
\hline Yes & 34 & 68 \\
\hline \multicolumn{3}{|c|}{ 5. ISB (Information seeking behavior) } \\
\hline Low & 24 & 48 \\
\hline Medium & 22 & 44 \\
\hline High & 04 & 08 \\
\hline \multicolumn{3}{|c|}{ 6. Distance from home to work place $(\mathrm{Km})$} \\
\hline Less(Less than 14) & 14 & 26 \\
\hline Medium (15-50) & 21 & 40 \\
\hline High(Higher than 50) & 18 & 34 \\
\hline
\end{tabular}

The pace of life is getting faster. What was new yesterday is already old today. Technology is changing, so are social habits, values, social structures and people. Because of that updating knowledge is very important to work efficiency. Unfortunately, significant number of respondents $(48 \%)$ was in low level of updating knowledge, while $44 \%$ were in moderate level and only $8 \%$ were in high stage.

Job title is one of the important aspects which directly influence the satisfaction of the employees in any organization. AG working under GS was call as "Development Officer". Though the common designation is Development Officers, it could be quietly differ in according with the department they work. As an example AGs who are working under the 
Ministry of Youth Affairs call as Youth Service Officer. Other example is AGs who are working under the Ministry of Technology and Research call as Science and Technology Officer. It was recorded that more than $50 \%$ respondents dissatisfied regarding their designation name.

Job description of the employees is also one of the important aspects of the job satisfaction. Out of 50 respondents, only $28(56 \%)$ knew their job profile. The rest 22 were not aware about their job profile. Among the selected group 26 respondents had pointed out that their work load is excessive and also not related with their education.

About $12(24 \%)$ of the sample had very low dedication regarding their job as well as another 12 (24\%) had high dedication. This could be due to negative attitude and low job satisfaction. Therefore the authorities should take action to provide appropriate measures for increasing their JS in order to increase AG dedication toward job. Majority of AGs $(55 \%)$ perceived their workload as average. Further, majority $(60 \%)$ of the respondents have indicated that more duties assumed by their supervisors are not relevant to their duties. Distance from home to work place is one of the important variables which directly correlate with the job satisfaction. Mean distance was recorded as $19 \mathrm{~km}$ from home to workplace. Around $44 \%$ of the sample pointed out that facilities provided by the institute to carrying out the duties were not enough while $48 \%$ indicated that facilities available were moderate.

The study helped develop suggestions to increase the JS of AG. Salary and awareness about job description showed positive significant relationship with job satisfaction while experience had showed negative significant relationship with job satisfaction. Other personal and job related variables were not correlated with job satisfaction.

\section{CONCLUSION AND RECOMMENDA- TION}

Majority of the agriculture graduates recruited under the graduate scheme found to be dissatisfied in their job as a result of the low salary, insufficient payment relate to their education level, poor performance appraisal, low availability of facilities and resources at work place, low recognition for creative works, low scope of appraisal based on performance, lack of opportunities for higher education and trainings and low promotion opportunities. This should be taken into account by the relevant authorities to provide suitable salary related to their education level, implement an appropriate performance appraisal mechanism, to provide at least basic facilities for the $A G$ and implementing appropriate promotion scheme to reach staff grade positions etc. It will help to get the maximum output from this young agriculture graduate to country.

\section{REFERENCES}

Alen et al 1998 Job Satisfaction \& human mind. In: Human Resource Management Theories. St peters Publ., UK. pp 120-132

Cranny S and Stone 1992 Deconstructing job satisfaction: separating evaluations, beliefs and affective experiences. In: Human Resource Management Review, Wilfred Publ., Vol 12, pp: 173194.

Donnelan MB, Trzesniewski KH, Moffitt TE, Caspi A and Robins RW 2005 Low Self-Esteem Is Related to Aggression, Antisocial Behavior, and Delinquency. Journal of Psychological Science Vol 16(4), pp 328-335.

Frederick Herzberg 1968 The hygienemotivation theory. Harvard Business Review, Vol 46 (1), pp 53-62

Manjula N 2000 A study on job perception, job performance and job satisfaction of AAOs in Karnataka. Ph. D Thesis University of Agricultural Sciences, Bangalore. 
Nagananda C 2005 Study of organizational climate perception of Assistant Directors of Agriculture and Agricultural officers of KSDA, M.Sc. (Agri.) Thesis, University of Agricultural Sciences, Dharwad.

Sandika AL and Silva KNND 2011 Relationship between Job Satisfaction and Organizational Climate: The Case of Agricultural Instructors (AIs) of the Department of Agriculture in Southern Province, Proceedings of the $8^{\text {th }}$ International Conference on Business Management, Organized by Faculty of Management Studies and Commerce, University of Sri Jayewardenepura. pp $1-8$. 